\title{
En el corazón de la política: viaje a las tinieblas del Estado
}

\section{In the heart of politics: Travelling to the darkness of the State}

\author{
JULIÁN SAUQUILLO \\ Universidad Autónoma de Madrid
}

RESUMEN. La última publicación de Antonio Rivera, El dios de los tiranos, es un archivo filosófico completo de las tentaciones del Estado de alcanzar una soberanía absoluta entre la Edad Media y Contemporánea. Su análisis de las doctrinas políticas fundamentales pone de manifiesto tres pasiones históricas - absolutismo, contrarrevolución y totalitarismoculminadas en el nacionalsocialismo y en la transfiguración teórica de Carl Schmitt. La parte polémica con esta aportación demanda explicar cómo la secularización de ciertos conceptos políticos - representación, demos, soberanía del pueblo, división de poderes...en las democracias modernas exige lealtad, confianza o algún credo para la democracia liberal como contrapunto necesario de los absolutismos de todos los tiempos.

Palabras clave: absolutismo, contrarrevolución, totalitarismo, secularización, representación.

A veces los libros se incardinan dentro de una investigación realizada dentro de un grupo extenso de investigación y son el resultado de más de una década de trabajo personal. Éste es el caso de la última publicación del profesor Antonio Rive$\mathrm{ra}^{1}$. Su libro es un recorrido de largo aliento a través de la Historia Moderna y Contemporánea por una de las tentacio-
Abstract. Antonio Rivera's last publication, El dios de los tiranos, is a philosophical archive of the temptations of the State to get absolute sovereignty between Middle and Contemporary Age. His analysis of the fundamental political doctrines shows three historical passions — absolutism, counterrevolution and totalitarianism - which culminate in National Socialism and Carl Schmitt's theoretical transfiguration. The controversial of this view asks for explaining how the secularization of some political concepts - representation, demos, sovereignty of the populate, division of powers... - in modern democracies, needs from loyalty, trust or some creed in comparison with all the absolutisms.

Key words: absolutism, counterrevolution, totalitarianism, secularization, representation.

nes no por más quiméricas menos constantes en el Estado: la detentación de una soberanía absoluta. El absolutismo, la contrarrevolución y el totalitarismo son las tres manifestaciones más señaladas de esta tentación estatal. La tentación del omnipotente se cruza, también en el caso del Estado, con el sentimiento de suma inseguridad. El soberano más pretencioso 
siempre se mostró capaz de todo y vulnerable a todos los ataques, por lo menos, desde el lamento del tirano Hierón ante el poeta Simónides por las continuas conspiraciones, confabulaciones y traiciones, en general, a que está sometido por parte, incluso, de la corte de los más leales. Cualquier rostro antropomórfico del Estado, como de la divinidad, ofrece una suma de pasiones intestinas que van de la venganza al disimulo, pasando por el temor. Nietzsche acertó al sospechar - en Así habló Zaratustra - que la verdadera pasión estatal no fuera representar la voluntad del pueblo como afirma con toda la faz del mentiroso. Si bien, no captó, quizás, todo el voluntarismo y el apasionamiento mostrado por el Estado, cuando tachó al Estado (prusiano de la época de Guillermo I) como «monstruo frío». El solitario de Sils-Maria se percató con total agudeza de que una llamada al pueblo soberano como auténtica voz del Estado sólo podía ser apelada como parte de una teología política para la democracia. Pero no hizo la clasificación de todas las pasiones de ese monstruo frío con el que representó al Estado.

Apenas se había realizado, hasta ahora, un recorrido tan complejo y amplio, entre nosotros - con la excepción muy singular de J. A. Fernández Santamaría ${ }^{2}$ - por las pasiones tiránicas más intestinas de desplegar un poder ilimitado a la manera de la más alta divinidad. El punto de arranque del estudio de Antonio Rivera es una preocupación más filosófica política que histórica: la República de Weimar (1919-1933) en la encrucijada de construir la Constitución racional que cierre las heridas abiertas sobre le cuerpo político alemán o dejarse arrastrar, por el contrario, por la tempestad revolucionaria de uno y otro signo - espartaquista o nacionalsocialista - que la acabará descomponiendo. Desaparecido Weber en los comienzos de este crucial momento, nadie como Carl Schmitt representa esta tensión, saldada, en su caso, en forma distinta al sabio de Heidelberg. La teología política de Schmitt representa el afán teórico y práctico - la voluntad de poder- más firme de recomponer una autoridad nacional totalitaria por encima de las divisiones partidistas reflejadas en el parlamentarismo posterior a la Primera Guerra Mundial. Antonio Rivera ha trazado en extenso y rigurosamente la ambición política de construir una voluntad política unitaria e ilimitada en el absolutismo, la contrarrevolución católica y el totalitarismo, frente a la fisura abierta en este monismo político por el protestantismo, reflejada en el mismo Hobbes y, de forma más palmaria, en el Tratado teológico-político de Baruch Spinoza. Ha seguido un método filosófico, persiguiendo el rigor para revelar cómo la teología política se desvía de la verdad en beneficio del bien de la comunidad sustentado en la creencia en la revelación divina. Su método sigue, en buena medida, esta dualidad de filosofía y teología tan defendida por Leo Strauss. La filosofía debe aspirar a la verdad aunque sea contraria a los intereses de la ciudad. Su método es certeramente develador de los sofismas teológico-políticos. En buena medida, ha rastreado el mayor número de fuentes clásicas de la teoría política con la clave interpretativa schmittiana para mostrar las trasformaciones del concepto de soberanía desde la división entre potentia $a b$ soluta y potentia ordenata hasta la configuración final del Estado administrativo como Estado total en el nacionalsocialismo. Su recorrido filosófico político da cuenta de la unificación política y del continuo riesgo de fractura política en los momentos estelares de la política - a decir de Schmitt en los momentos excepcionales de la política como el representado por la República de Weimar paradigmáticamente. Este estudio analiza 
sucesivas batallas históricas de la teología política con el caos de las guerras civiles. Desde presupuestos schmittianos, da cuenta de cómo, cara a evitar la guerra civil entre Estados, ha predominado un nomos o estado de fuerza ilimitado, no regido por el ius gentium clásico. Rivera afronta el estudio de esta indeseable fisura, en términos políticos, desde el conocimiento previo del protestantismo político mostrado en Republicanismo calvinista $(1999)^{3}$. Su último libro muestra también un declarado compromiso con la democracia liberal — división de poderes, pluralismo y sistema de partidos- como alternativa deseable al monismo absolutista, representado, sobre todo, por Jean Bodin $\mathrm{y}$ el catolicismo reaccionario $\mathrm{y}$ contrarrevolucionario. Al autor de Los seis libros de la República no le parece concebible una esfera privada ajena al dominio del monarca: los pensamientos de los súbditos contra el tirano son de difícil castigo por ser internos, pero son, en todo caso, pecados de lesa majestad y se castigan con la muerte.

Rivera ha situado su análisis de conceptos fundamentales de la tradición política - representación, soberanía,...en el marco de lo que denomina el «gran teorema de la secularización». Dentro de este teorema no resulta operativo un concepto débil de secularización — tránsito de un estado religioso regular a un estado secular y expropiación de los bienes temporales de la Iglesia a manos secularessino el concepto filosófico que no admite se haya superado, en la Modernidad, una configuración simbólica de la sociedad mediante nexos y trazos religiosos. Lo que ha sucedido, más bien, si seguimos un concepto fuerte de secularización, es un traspaso de los contenidos religiosos a la esfera secular coincidente con la amortización de la herencia cristiana. Este carácter paradójico de la secularización moderna al autor de El dios de los tiranos le parece puesto de relieve en la filosofía de la historia de Hegel y en la teología política schmittiana en grado sumo. Su complejidad fue puesta de manifiesto singularmente por Ernst H. Kantorowicz - como recuerda Rivera- cuando distingue, en Los dos cuerpos del rey. Un estudio de teología política medieval, entre secularización cristiana, imperial y pagana. Todo el argumento de Rivera participa de un balance crítico de cualquier ilusión de secularización perfecta en la modernidad. Tanto este como otros libros suyos, precedentes, tienen un horizonte común en el diagnóstico weberiano del proceso de hiperracionalización: si bien la tecnificación de la sociedad moderna es ineluctable, la pervivencia de elementos irracionales en la sociedad desarrollada es palmaria. Dentro del análisis de la acción política, predomina la legitimidad legal racional si bien —como puso de manifiesto la sociología comprehensiva- con una existencia efectiva de la legitimidad carismática.

De esta forma, la secularización moderna de la política consistió en el tránsito de las cualidades divinas de Dios al príncipe soberano. Kelsen había advertido de tres teologías políticas directamente enfrentadas a su teoría pura del derecho: las de Feuerbach, Freud y Durkheim. Pero la más amenazante en su época es la teología schmittiana. La teoría pura del derecho había afirmado la precedencia del derecho respecto del Estado - con conciencia de ser una afirmación contraintuitiva- dado que sólo el derecho es criterio heurístico capaz de señalar qué acciones públicas son eminentemente estatales y cuáles no poseen ningún interés estatal. Lo cierto es que Hans Kelsen acabaría aceptando con toda probidad intelectual que es necesaria una voluntad política previa al Estado y al derecho que los cree. Mientras que, mucho antes de esta demostración de honestidad intelectual, Carl Schmitt afirmaría, fe- 
rozmente, la latencia social de un poder constituyente que da continuidad y quiebra a las Constituciones en cada proceso histórico revolucionario. Como señala Rivera, Hans Kelsen contribuyó al proceso de despersonalización liberal del derecho con el consiguiente desinterés por los períodos históricos de excepcionalidad política, mientras Carl Schmitt subrayó el acontecimiento excepcional en la historia como situación estelar de la política que concede la gran oportunidad de resolver el desorden al auténtico soberano, instituyendo por la fuerza una nueva situación de orden, de normalidad, un nomos que selle la paz y evite la guerra fratricida. El estado de guerra, para Schmitt, es permanente pues la sustancia de todas las políticas - liberales, ilustradas, reaccionarias, conservadoras, autoritarias, socialistas...- es la división ontológicamente dada entre amigo/enemigo. Para Schmitt lo que manifiesta el tránsito de la paz a la guerra es el paso de la situación de guerra virtual a guerra real. Es el auténtico soberano, no sometido a ley alguna, quién determina cuándo un enemigo interior o exterior amenaza su soberanía y debe pasar al estado de guerra civil o internacional real.

La genealogía trazada por Rivera fundamentalmente de los conceptos de soberanía y representación en este proceso de secularización imperfecta tiene que remontarse a la potestas absoluta de Jean Bodin. Nadie mejor que él formuló en su tiempo la urgente pregunta acerca de cómo remontar las guerras entre católicos y hugonotes para formar una soberanía unitaria e ilimitada. Coincide con Shakespeare y Vives en la necesaria consolidación de la jerarquía social contra las rebeliones y las guerras civiles encarnadas como utopía negativa de anarquismo en la ciudad de Münster. Pero entre tales pares, no deja de ser el mayor valedor de la seguridad y prosperidad de la comunidad, incompatible con la multitudo disgregada.
Todo extranjero o es enemigo o es esclavo. En el autor de Los seis libros de la República se encuentra una elaboración constitucional autónoma de la ilimitada y perpetua soberanía del monarca, a la manera de un Dios secularizado, que no responde ante las leyes positivas de los hombres y, a su vez, - nos recuerda Riverauna concepción de la soberanía todavía inscrita, como autor de tránsito, en el orden tradicional. Uno de los aspectos más apasionantes de este tránsito es, en mi opinión, cómo Jean-Jacques Rousseau rehace la elaboración teórica de la soberanía realizada por la doctrina jurídica medieval para abordar, de nuevo, una concepción unitaria y sin fracturas de la soberanía. Y, en relación con el concepto de representación política, Rivera aborda las tesis schmittianas de Catolicismo y forma politica cuando el iuspublicista alemán exalta la representación de la Iglesia como única representación verdadera. Schmitt subrayó la estela representativa del Papa frente a la representación, supuestamente, sin brillo alguno de la Asamblea Nacional francesa surgida de la gran Revolución.

Rivera ha elegido muy bien el objetivo de sus críticas a una concepción de la soberanía que no admite el pluralismo político ni la división de poderes. Desde la teoría de la soberanía de Jean Bodin, como dominio inscrito del soberano sobre sus súbditos a la manera del padre de familia que guarda una relación sanguínea y cerrada sobre la familia con los hijos, Schmitt representa la culminación totalitaria de la soberanía a partir del catolicismo. Para Schmitt, la complexio opositorum del catolicismo es unión absoluta de los más extraordinarios contrarios bajo el dominio de un poder común. Mientras que Hobbes y, sobre todo, el judío Spinoza son los cómplices de una complacencia con la reforma que introduce fraccionamiento político en la deseable unidad del poder absoluto, al diferenciar entre esfera pública y 
esfera privada y destinar estrictamente aquélla a ser controlada por el poder del Estado. Del imperio inglés sobre el mar, Rivera extrae las acertadas conclusiones en el plano internacional acerca de la fractura acontecida del poder absoluto sobre la tierra. Como en un sentido más general, conviene detectar la fractura de la voluntad política en el reconocimiento hobbesiano de la variedad de doctrinas en la misma comunidad que se configura a la manera de una Iglesia, en el plano interno. En este libro, Rivera pone de manifiesto cómo la reacción contrarrevolucionaria católica vino a suturar en términos teóricos las divisiones abiertas por el protestantismo asumido por Hobbes, dentro de una tradición culminada doctrinariamente por la teología política de Carl Schmitt. Toda la máquina de guerra schmittiana se pone en movimiento teórico contra la supuesta indecisión del liberalismo para solventar los estados de excepción y frente al derecho internacional y los derechos humanos por suponer límites a una actuación ilimitada del Estado concebido como divinidad - como El dios de los tiranos explica de forma muy solvente.

Su compromiso democrático no quita que Rivera, por momentos, como el señor Kurtz de El corazón en las tinieblas de Joseph Conrad, se haya visto seducido por el mal o por el más malvado en esta caso: el antimaquiavelismo maquiavélico de la reacción católica. No seducido moral o políticamente sino lógicamente. A veces atribuye mayores logros a los escritores del barroco que al [ $\dot{i}$ "extremadamente ingenuo»? (pág. 122)] Maquiavelo. Creo que los mayores malvados hacen estragos entre los teóricos bondadosos como nosotros, después de todo. Maquiavelo es indudablemente parte del proceso de secularización que distingue a la política de la religión. Es seguro que forma parte de esa tradición pagana que vio en el artista al auténtico soberano en vez del pusilánime Papa. Pero ni estoy seguro de que la recepción tacitista en España sea posible en el siglo XVII sin Maquiavelo, inspirador del barroquismo político aunque sea en el rechazo, ni creo que no exista en «Il Machia» consideración acerca de los momentos de excepcionalidad política con toda la crudeza de la responsabilidad política en el mal. Los capítulos XVII y XVIII del Libro I de los Discursos sobre la primera década de Tito Livio (1513-1518) se refieren a los momentos de excepcionalidad política en la deteriorada república. Allí distingue entre el tirano y el príncipe republicano. El primero incapaz de metamorfosis alguna de malo y despótico a buen republicano; el segundo capaz de la metamorfosis del buen príncipe que acarrea la responsabilidad de adoptar las peores medidas durante una dictadura provisional que restituya a la republica sobre el daño ocasionado al cuerpo político por las más degeneradas costumbres. Para pasar, de nuevo, refundada la república, de príncipe malvado a buen republicano. Maquiavelo no se llama a engaño al pensar que si la primera trasformación moral es imposible, la segunda es bien difícil. Pero Antonio Rivera ha sostenido el argumento sobre la excepcionalidad política más bien en las Consideraciones sobre los golpes de Estado de Gabriel Naudé y a los Edictos de pacificación y de Nantes de Enrique IV. Sin embargo, ¿no se consideraba Carl Schmitt el Maquiavelo del siglo XX? ¿Hubiera sido posible el antimaquiavelismo maquiavélico del siglo XVII sin los arcana imperii de Maquiavelo? La exposición dedicada al emperador volteriano Federico II realizada por Antonio Rivera es estupenda aunque a veces atribuya mayor talento para la excepcionalidad política, en el plano teórico, al emperador que a Maquiavelo - en el plano práctico nadie tiene duda de que más valen aquellas armas que estos consejos-. Pero 
Roberto R. Aramayo ha despejado las dudas que pudiéramos tener sobre el antimaquiavelismo maquiavélico de Federico II ${ }^{4}$. Y, aquí, creo que vale más el original que la copia, por más que nos seduzca el doble valor filosófico y militar del guerrero de Sans Souci.

De entre las interpretaciones de Hobbes, Antonio Rivera opta, creo que acertadamente, por la absolutista. Hobbes es el constructor teórico de la «existencial representación soberana» mediante la diferenciación vertical entre el monarca y los súbditos. El autor de el De cive todavía no reflexiona sobre la representación constitucional sino sobre la representación existencial —aquí Rivera sigue a Vögelin- como unidad política absoluta bajo la figura del representante soberano. Pero Hobbes — sigo a Schmitt y a Rivera en su acertada interpretación del Leviatán schmittiano - también es el responsable de la brecha liberal en el Estado al distinguir entre la «esfera externa» de sumisión absoluta a la autoridad soberana y la «esfera interna» donde cabe la libertad individual y el disentimiento con la autoridad pública. Sin embargo, la representación constitucional -in pacem Rivera o Vögelin — no deja de ser representación de unidades orgánicas - ya sea de la asamblea estatal, autonómica o localpor encima de la representación de intereses o de partidos reflejados en el cuerpo político.

Incluso en las concepciones más liberales del «viejo Mill» — como le llama Weber a John Stuart Mill_ - se requiere la constitución de un demos —a cargo del poder constituyente - que procede de un acto de dominación y poder por el que las decisiones de los representantes políticos son de obligado cumplimiento de todos aquellos que quedan irremediablemente adscritos a esa identidad política, independientemente de que hayan podido negociar su entrada o no. No puede ser de otro modo y me malicio que la representación existencial y la representación constitucional tienen un parentesco teórico no muy lejano. Hay identidades nacionales representadas verticalmente que se imponen necesariamente en democracia incluso a quienes no existían físicamente en el momento de aprobación mayoritaria de la Constitución. Y es necesario compartir esa identidad nacional o demos para que la Constitución sea deseablemente obligatoria por un tiempo tan largo como refleja que haya sido creada con unos mecanismos agravados de reforma. La superposición de la Constitución sobre la soberanía del pueblo, incluso en el liberal Estado Constitucional de Derecho, requiere de un momento constituyente en que se construye la existencia metahistórica de ese demos obligado por las decisiones de representantes elegidos y vencedores en mayorías parlamentarias y de gobierno. La propia representación constitucional es diseñada como representación de una identidad nacional que se impone (democráticamente) sobre intereses e individuos con serios desacuerdos sobre cuestiones trascendentales.

¿Están tan lejos la representación constitucional y la representación existencial si no fuera porque en aquélla los individuos contamos con derechos fundamentales como garantías individuales? La construcción de un demos identitario - existencial — se hace imprescindible también con la Constitución como garante de derechos fundamentales. No puede ser de otro modo, probablemente. Ha sido Marcel Gauchet quien advirtió de cómo en la Revolución Francesa los derechos humanos surgen como principios últimos de justificación del poder ilustrado frente al poder monárquico más que como garantías de los individuos frente al Estado. El mismo surgimiento de los derechos de seguridad de sostenimiento del hambriento supuso un intento jacobino 
- en el surgimiento de la «cuestión social»—- de asegurar la obediencia del ciudadano. Porque hay derechos para quien no puede asegurarse la subsistencia por sí mismo hay inapelables deberes de éstos para con el Estado ${ }^{5}$. Los derechos humanos, cuando se reducen a su versión institucional y no adquieren virtualidad reivindicativa como «exigencias morales» (Javier Muguerza ${ }^{6}$ ), forman parte de esta estrategia soberanista y unificadora. Aunque haya, claro está, una diferencia obvia entre una teoría de la autoridad absoluta y una teoría de la autoridad democrática, ambas unifican muy decisivamente. Y esta conclusión nos advierte de la imposible secularización total de nuestros sistemas políticos de un «cuerpo místico» que opera dentro de una teología política también para la democracia. Antonio Rivera afirma que el sistema constitucional se aleja de la teoría absolutista mediante la afirmación de los derechos humanos como triunfos históricos [recoge expresamente la teoría de Georg Jellinek sobre el origen de los derechos humanos en Alemania y Estados Unidos como garantías de los individuos (pág. 249)] pero el soberanismo de la teoría constitucional es más persistente de lo que parece en general. Incluso en un Estado Constitucional liberal más perfecto como el norteamericano - al que se refiere Antonio Rivera (pág. 250)_, que luego se irradia al viejo continente en el período de entreguerras, las deficiencias de la Convención General, sin trabajadores, negros y mujeres, deja mucho que desear como liberal. Hemos de ver la división de poderes - como nos recuerda Bartolomé Clavero - más por el nominativo de «poderes» que por el adjetivo de «legislativo», «ejecutivo»y «judicial». Antonio Rivera opone el laicismo, la división de poderes y el pluralismo como logros genuinos al espíritu contrarrevolucionario (pág. 266). Sí, son tres poderes, pero, en todo caso, el primero es el legislativo. Joaquín Costa diría que, durante todo el siglo XIX ${ }^{7}$, dominado por oligarcas, caciques y gobernadores civiles, dentro de una concepción unitaria de intereses nobiliarios ${ }^{8}$. No soy muy optimista sobre este pasado más reciente. La polémica Locke-Filmer ( $E l$ dios de los tiranos, págs. 163-167) dejó —en el argumento desarrollado por Bartolomé Clavero - para la historia un reparto de funciones donde uno y otro pensamiento se reforzaban: las libertades individuales de Locke quedaron para los hombres, blancos y propietarios; mientras que el paternalismo de Filmer se destinó a los colonizados que no contaban con inteligencia para poseer mayoría de edad política ${ }^{9}$ (no hace falta sino ver las afirmaciones de John Stuart Mill justificando las reducciones jesuíticas para los nativos paraguayos). Además, la Revolución Francesa dejó un balance, incluso, de mayor soberanismo y perpetuó el Estado Legislativo durante todo el siglo XIX con un poder constituyente que no se acaba de cerrar en una organización garantista de poderes y quiebra las Constituciones en una auténtica lucha de poder en todos los frentes. Sólo como un dogma constitucional puede generalmente aceptarse que en la Francia revolucionaria hay Constitución en 1791, porque allí se recoja un artículo XVI que señala, expresamente, que para que haya Constitución debe darse división de poderes y respeto de los derechos humanos ${ }^{10}$. Esta observación mía - posiblemente fuera de los objetivos teóricos del libro de Rivera ${ }^{11}$ cuando deslinda la democracia de concepciones clásicas de la soberanía - no obvia un esfuerzo muy original y sugestivo por reconstruir, dentro de la teología política absolutista y católica, este corpus mysticum (corpus Eclessiae mysticum o corpus Reipublicae mysticum) entre los argumentos de John Fortescue, Jean Bodin, 
Thomas Hobbes, Robert Filmer, Blaise Pascal y la Compañía de Jesús (fundamentalmente Francisco Suárez).

El dios de los tiranos acierta en deslindar la concepción de la soberanía hobbesiana y schmittiana de la teología medieval que distinguía entre la doble potentia: ordenata y absoluta. La reforma protestante es la matriz genealógica de la potentia absoluta querida por Hobbes para su Leviatán y que, previamente, había sido ordenata para la Compañía de Jesús ${ }^{12}$. Para Schmitt, si existe Providencia, todo poder es bueno pues Dios está tras su ejercicio. Schmitt es el valedor de una concepción de la soberanía construida frente a la brecha liberal que Hobbes abre hacia el constitucionalismo liberal. El «Dios de los Tiranos» es la potentia absoluta encarnada en un hombre y deificada como divinidad humana independiente de Dios. Aunque el «poder absoluto» como libertad divina ya la encontramos en la Baja Edad Media, la Contrarreforma del siglo XVII atribuyó esa diabólica concepción de la espiritualidad divina a Maquiavelo y a los maquiavelianos como Gabriel Naudé. Autores como Saavedra Fajardo o Ribadeneira coinciden en criticar a Maquiavelo por hacer de la política una esfera autónoma que puede servirse de la religión como un medio. Antonio Rivera realiza un magnífico prontuario de las habilidades que debe activar el político barroco para adaptarse a los espejos de príncipes de la época. Grocio y Naudé justificaron las mentiras en política. Mientras que el catolicismo barroco se mantuvo plagado de incertidumbres, Baltasar Gracián se mostró partidario de endulzar las verdades más terribles. Y compartió con Saavedra la necesidad política de mantener los secretos y misterios bien guardados. Sólo el jesuitismo político aceptó la doblez — no el engaño - en la lucha contra el pecado por su defensa de la adaptación al enemi- go para vencerlo. Gracián justifica, incluso, la mentira para contrarrestar al mentiroso. El capítulo dedicado a las habilidades políticas de Floridablanca, los dilemas morales y político-diplomáticos de Saavedra y el antimaquiavelismo maquiavélico de Federico II está muy bien construido y es sumamente sugerente. De todas estas habilidades inmortalizadas tan sabiamente por nuestro Siglo de Oro, me parece la más memorable la apuntada por Walter Benjamín para buenos políticos como Fernando el Católico: han de ser como un «estoico radical» capaz de «violentar sus pasiones» (un alma tiránica dominada por las pasiones tiene que ser tan implacable consigo mismo en el dominio interno como lo es con el exterior en el estado de excepción). Carl Schmitt vio en este arsenal barroco de argucias y habilidades un baluarte donde remontar el fracaso del absolutismo para cerrar un poder verdaderamente unitario y no dotado de dos esferas, como el postulado por el spinozismo. El caballo de Troya del fuero interno - señala Rivera con toda lógica - destruyó al Estado absolutista desde dentro. Para Schmitt, la mayor victoria del absolutismo es apócrifa e inintencionada, incluso, pues abrió al Estado a los partidos. La libertad de conciencia privada — dentro de su lógicadejó paso al partidismo público. A los efectos de construir una auténtica teología política, más vale entonces el catolicismo que el absolutismo, pues justifica claro y alto que porque hubo pecado original y hay libertad individual debe haber jerarquía. Además, el catolicismo despotencia convenientemente la acción de los hombres ya que la historia progresa porque hay Providencia y no por los hombres, malos por naturaleza y castigados por Dios con sangrías revolucionarias. El catolicismo reaccionario supone una vuelta a una sola Iglesia frente a la proliferación de sectas y partidos políticos. 
Pero a los fines absolutistas del Estado total, Schmitt corrobora en el catolicismo un mayor absolutismo que en Hobbes pero una indeseable defensa de la potentia ordinata.

Uno de los aciertos del libro es desvelar la estrategia sofista seguida por Schmitt en su teoría jurídica y política. Cara a robustecer la soberanía absoluta del Estado, el autor de la Teoría de la Constitución emprende una ruda diatriba contra el liberalismo por despolitizar la vida social y enaltecer el mercado. El normativismo liberal, impulsado por los juristas judíos, sería responsable, dentro del argumento del célebre jurista nacionalsocialista, de favorecer la guerra civil al despotenciar un deseable nomos sobre la existencia permanente del conflicto en la tierra. El liberalismo es el origen inconveniente para Schmitt tanto de la ilusión de armonía económica en progreso ilimitado como de la indulgencia política ante la disputa violenta ineludible en la tierra. Estudiar a Schmitt hoy, con el fundamento dilatado de sus propias lecturas y de sus contemporáneos, como lo hace Rivera, supone situarse de una forma sumamente sugerente ante el nomos de la tierra y el mar desde la formación de la geopolítica en que nos encontramos. Rivera ha acompañado críticamente la explicación schmittiana del mapa geopolítico de las sociedades posrevolucionarias. Con una pasión teórica que refleja su vocación intelectual genuina, dice ser consciente de que la razón de Estado tuvo su cénit en el siglo XVIII y, sin atajos, emprende la reconstrucción del nomos de la tierra propio de la época hasta la guerra fría: de la guerra civil y la guerra internacional. Del nomos que asegura un equilibrio plomizo sobre cualquier guerra mundial a la aparición de estados intermedios entre la guerra y la paz. Schmitt ha sido un compañero de viaje válido de Rivera dentro del realismo político que aconsejan estos temas acerca de las guerras internacionales. Pero su propuesta normativa - Rivera es un profesor de ética dedicado también a la historia y a la teoría del pensamiento político — ha sido además muy cuidada. Me permito citar sus esclarecedoras palabras finales: «La obra de Schmitt arroja nueva luz si tenemos en cuenta que, en el fondo, el jurista alemán nos está relatando la lucha entre dos grandes monomitos. En esta batalla, el dios de la teología política, cuyos orígenes se remontan en parte hasta el $\mathrm{Le}$ viatán del absolutimo, se enfrenta al Behemoth de la guerra civil mundial, una de cuyas figuras más temibles es la huelga general proletaria teorizada por Sorel. Se trata, en contra de lo que opina el propio Schmitt, de la guerra mantenida por dos monoteísmos políticos: el de la teología política, que toma el dios de la potentia absoluta como referencia última; y el de la revolucionaria lucha de clases que adopta como principal modelo mítico al Prometeo cristiano, al Hijo que se revela contra la inexorable ley antigua y quiere ocupar el lugar del Padre. Contra estos mitos, cuyo fundamento es la lucha por la omnipotencia, tan sólo nos resta oponer la politeísta división de poderes, la vuelta una vez más a la prolijidad y al rodeo de la discusión, del litigio político y de los frágiles compromisos» (págs. 414). Comparto este deseo final que me hace recordar algunos pasajes maquiavelianos de los Discursos sobre la primera década de Tito Livio, donde «Il Machia» alaba las diatribas y las querellas en la república, que no deben ser confundidas con la calumnia en la vida política. Algunos - Berlin, sin duda - han visto el origen del liberalismo aquí. Quizás nos quede preguntarnos qué nos impide hoy esto mismo: los diálogos en la ciudad. ¿La propia teología política en que nos encontramos hoy? Estoy seguro de que Rivera nos sorprenderá con importantes re- 
flexiones sobre esta cuestión. Michel Foucault, a quien Rivera menciona con compartida admiración, señaló que no estamos bajo el signo del dominio que Maquiavelo, después de todo, nos reveló sino de otro todavía más tiránico que denominó «poder pastoral». Quevedo en Política de Dios, Gobierno de Cristo dio cuenta del mecanismo barroco de gobierno del rebaño temporal como si del Primer Rebaño se tratara. Foucault, más tarde, fue consciente de que, de la razón de Estado al liberalismo, sigue ejercitándose día tras día el mismo pastoreo de la grey, con diversos grados de intensidad. Con Rivera me gustaría seguir dialogando sobre las nuevas teologías políticas y de si podemos tener esperanza de ateísmo político o de si, por el contrario, cabe sólo ser «teólogo de una antiteología». Por el momento, mi descreimiento hacia las posibilidades reales de alguna política que podamos pensar no sea teológica es mayor que el suyo. Pero habrá ocasión de seguir. Ésta no es la primera pero tampoco será la última.

\section{NOTAS}

1 Antonio Rivera, El dios de los tiranos. Un recorrido por los fundamentos teóricos del absolutismo, la contrarrevolución y el totalitarismo, Almuzara, Murcia, 2007, 414 págs. El grupo de investigación donde se inscribe este libro es el dirigido por el profesor José Luis Villacañas Berlanga, articulado en torno a las Biblioteca Digital Saavedra Fajardo, impulsada fundamentalmente desde la Facultad de Filosofía de la Universidad de Murcia.

2 J. A. Fernández Santamaría, El Estado, la guerra y la paz (1977, traducción del original inglés: 1988), Razón de Estado y Política en el pensamiento del barroco (1595-1640) (1986), La formación de la sociedad y el origen del Estado. Ensayos sobre el pensamiento político español del Siglo de Oro (1997). J. A. Fernández Santamaría es Catedrático de Historia de California State University, Hayward.

3 Antonio Rivera, Republicanismo calvinista, Res publica, Murcia, 1999, 191 págs.

4 Roberto R. Aramayo, La quimera del Rey filósofo: los dilemas del poder o el frustrado idilio entre la ética y lo político, Taurus, Madrid, 1997, 174 págs.; Federico II, Rey de Prusia, Antimaquiavelo o Refutación del Príncipe de Maquiavelo (editado en 1740 por Voltaire; introducción, traducción y notas de Roberto R. Aramayo), Centro de Estudios y Constitucionales, 1995, LVIII+205 págs.

5 Marcel Gauchet, La Révolution des droits de l’homme, Gallimard, París, 1989, 341 págs.

${ }^{6}$ Muguerza, Javier (y otros autores), El fundamento de los derechos humanos (edición preparada por
Gregorio Peces-Barba Martínez), Debate, Madrid, 1989.

7 Fioravanti, Maurizio, Appunti di storia delle constituzioni moderne. Le libertà fondamentali, G. Giappicheli Editore, 1995 (presentación de Clara Álvarez y traducción de Manuel Martínez Neira, Los derechos fundamentales. Apuntes de historia de las Constituciones, Madrid, Trotta, 1996 (4. ${ }^{a}$ ed. 2003), 165 págs.).

8 Joaquín Costa, Oligarquía y caciquismo: como la forma actual de gobierno en España: urgencia y modo de cambiarla, Biblioteca Nueva, Madrid, 1998 (también en Ministerio de Trabajo; introducción y notas de Alfonso Ortí). Vid. Sobre este tema, Antonio Rivera, Reacción y revolución en la España liberal, Biblioteca Nueva, 2006, 355 págs.

${ }^{9}$ Bartolomé Clavero, El Orden de los Poderes. Historias constituyentes de la Trinidad Constitucional, Trotta, Madrid, 2007, 321 págs.

10 Blanco Valdés, Roberto, El valor de la Constitución. Separación de poderes, supremacia de la ley y control de constitucionalidad en los orígenes del Estado liberal, Alianza Editorial, Madrid, 1998, 384 págs.

11 Puede que mis observaciones se encuentren más cerca de investigaciones como la desarrollada por Alfonso Galindo Hervás en La Soberanía. De la Teología Política al Comunitarismo Impolítico, Res Publica. Estudios de Filosofía Política, Murcia, 2003, 268 págs.

12 Antonio Rivera, La política del cielo: clericalismo jesuita y Estado moderno, Hildesheim, Olms, 1999, 177 págs. 